\title{
Regional Colonic Transit Pattern Does Not Conclusively Identify Evacuation Disorders in Constipated Patients with Delayed Colonic Transit
}

\author{
Seon-Young Park, Duane Burton, Irene Busciglio, Deborah Eckert, and Michael Camilleri* \\ Clinical Enteric Neuroscience Translational and Epidemiological Research (CENTER), Division of Gastroenterology and Hepatology, Mayo Clinic, \\ Rochester, MN, USA
}

\section{Background/Aims}

After exclusion of structural diseases, chronic constipation may be associated with normal or slow transit or rectal evacuation disorders. We evaluated: (1) clinical features and anorectal function, (2) difference of regional colonic transit according to the presence or absence of evacuation disorders, and (3) association of colonic transit with gender in patients with objectively slow colonic transit.

\section{Methods}

We reviewed electronic medical records of 1553 patients with constipation seen by one gastroenterologist from 1994-2015 at a tertiary medical center. We identified patients with slow colonic transit using scintigraphy. Evacuation disorders were identified on clinical examination or anorectal manometry. Colonic compliance and tone were measured in 29 patients. Statistical analysis was by the Mann-Whitney rank sum test.

\section{Results}

Of the 207 patients (155 females, mean age $41.3 \pm 15.3$ [SD] years), 113 had evacuation disorders (ED+ve) and 94 did not (ED-ve). There were no significant differences in colonic transit or gastric emptying between ED+ve or ED-ve; similarly, colonic compliance, tone and responses to neostigmine were not different in ED+ve and ED-ve. Conversely, there were significant differences by gender in patients with slow colonic transit: colonic transit, small bowel transit, and gastric emptying (all $P<0.005$ ).

\section{Conclusions}

Delayed colonic transit does not exclude evacuation disorders in chronic constipation. In chronic constipation and objectively slow colonic transit, females had slower gastric, small bowel, and colonic transit than males.

(J Neurogastroenterol Motil 2017;23:92-100)

Key Words

Colon; Constipation; Gastric emptying; Gastrointestinal transit; Rectal disease

Received: April 18, 2016 Revised: July 6, 2016 Accepted: August 21, 2016

(a) This is an Open Access article distributed under the terms of the Creative Commons Attribution Non-Commercial License (http://creativecommons. org/licenses/by-nc/4.0) which permits unrestricted non-commercial use, distribution, and reproduction in any medium, provided the original work is properly cited.

*Correspondence: Michael Camilleri, MD

Mayo Clinic, Charlton Building, Rm. 8-110, 200 First St. S.W., Rochester, MN 55905, USA

Tel: +1-507-266-2305, Fax: +1-507-538-5820, E-mail: camilleri.michael@mayo.edu

Seon-Young Park is a Visiting Scientist at CENTER, Mayo Clinic. Her home institution is Chonnam National University School of Medicine, Division of Gastroenterology, Department of Internal Medicine, Gwangju, Korea. 


\section{Introduction}

Chronic constipation is a common disorder with a prevalence of $2-27 \%$ in western countries. ${ }^{1,2}$ In a systematic review that reported the prevalence of chronic idiopathic constipation in 41 separate study populations (including 261040 subjects), the pooled prevalence of chronic idiopathic constipation in all studies was $14 \%(95 \%$ CI, 12-17\%), with lower prevalence in southeast Asian studies. ${ }^{3}$ In a population-based study conducted in Olmsted County, Minnesota, the cumulative incidence of chronic constipation over a 15 -year period (1988 to 2003) was $17.4 \% .{ }^{4}$ After exclusion of structural diseases, there are three large categories or subgroups of patients with chronic constipation: normal transit constipation, slow transit constipation, and rectal evacuation disorders or dyssynergic defecation. ${ }^{5}$ Evacuation disorders were associated with delayed overall colonic transit and ascending colon half-emptying times ( $\left.\mathrm{AC}_{1 / 2}\right)$ compared to healthy controls. ${ }^{6-8}$ In addition, our prior study had suggested that the regional colonic transit profile may differentiate evacuation disorders or slow transit constipation, chiefly by the predominant location of the isotope in the colon at 48 hours. Thus, isotope presence was predominantly in the left colon in patients with evacuation disorders who had either normal or delayed overall colonic transit, and the isotope was predominantly in the ascending and transverse colonic regions in slow transit constipation patients with evacuation disorders. ${ }^{6}$ In the current analysis, we focused exclusively on patients with slow colonic transit in order to clarify whether the regional colonic transit pattern is useful in identifying evacuation disorders in constipated patients, since there is limited information about regional colonic transit between those patients with slow colonic transit compared to those without evacuation disorders.

In this study, we aimed to evaluate: (1) clinical features and anorectal function, (2) differences in regional colonic transit according to the presence or absence of evacuation disorders, and (3) association of colonic transit with gender in patients with objectively slow colonic transit.

\section{Materials and Methods}

\section{Study Population}

This was a review of the medical records of patients who had previously given their unrestricted consent for use of their medical records for research studies. The Mayo Clinic Institutional Review Board approved the study (IRB No. 16-000703). Electronic medi- cal records at Mayo Clinic in Rochester, MN, USA were reviewed to find all potential patients seen by a single gastroenterologist (M.C.) inclusive of dates January 1, 1994 to December 31, 2015. This was an update of a paper we had published previously of 1411 patients with a diagnosis of constipation from January 1, 1994 to June 30, 2011. ${ }^{6}$ This paper added a second cohort that included 142 patients with a diagnosis of chronic constipation seen from July 1, 2011 to December 31, 2015. Among a total of 1553 patients, 207 had slow colonic transit by scintigraphy (CT geometric center at $24 \mathrm{~h}$ of $<1.7$ or $<3.0$ at 48 hours). ${ }^{9}$ Among the 207 patients with slow colonic transit, 31 patients did not present any symptoms or physical examination findings ${ }^{5}$ that would be consistent with evacuation disorders. Among 176 patients who underwent anorectal manometry for evaluation of evacuation disorders, 113 were identified with evacuation disorders and 63 without evacuation disorders (Figure), based on: (1) a balloon expulsion test that was abnormal (that is, the patient was unable to expel a balloon that had $<200 \mathrm{~g}$ of weight added from the rectum) and/or (2) high resting anal pressure (maximum resting pressure $>90 \mathrm{mmHg}$ ). ${ }^{10}$ These 2 criteria

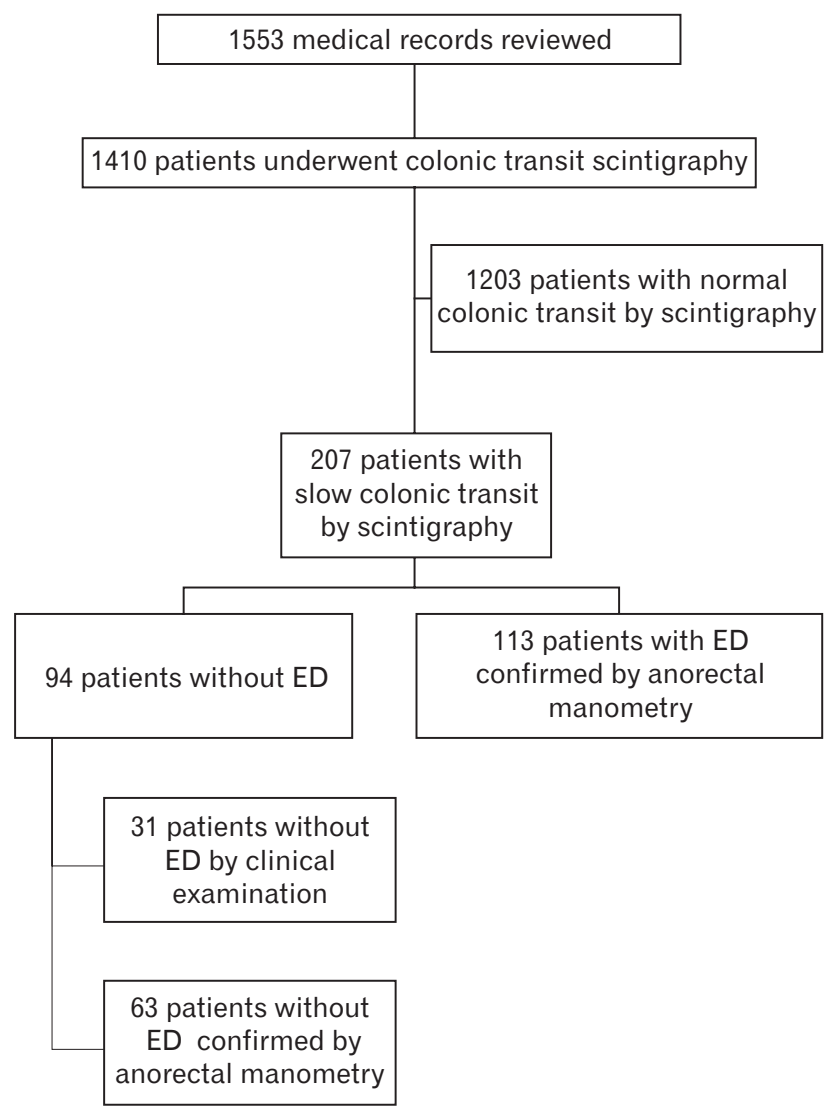

Figure. Flow sheet for this study. ED, evacuation disorders. 
were developed from a review of the published data for adults studied in Minnesota ${ }^{11}$ and Iowa. ${ }^{12}$

We also collected information about demographic features including body mass index (BMI), underlying disease status, history of prior abdominal surgery, and medication history.

\section{Procedures}

\section{Gastrointestinal and colonic transit measurements}

To evaluate gastric emptying (GE) and small bowel transit, an established scintigraphic method was used..$^{13}$ Abdominal images of 2-minute duration were obtained with anterior and posterior gamma cameras following ingestion of the ${ }^{99 \mathrm{~m}} \mathrm{Tc}$-labeled egg meal (296 kcal, 32\% fat) and 1, 2, and 4 hour (GE 1 hr, GE 2 hr, and GE 4 hr) clinical studies. Orocecal transit was assessed by the colonic filling of ${ }^{99 \mathrm{~m}}$ Tc-labeled egg meal at 6 hours. Colonic filling at 6 hours (CF6) is an indirect measurement of small bowel transit time.

We also simultaneously used a scintigraphic method that had been previously validated to evaluate colonic transit; especially, we focused on images taken at 4, 6, 24, and 48 hours. ${ }^{9,14}$ The colonic transit profile is assessed by calculating the geometric center (GC) at 24 hours and 48 hours (GC24 and GC48), and is expressed as the sum of the weighted proportion of ${ }^{111} \mathrm{In}$ counts in each of 5 colonic regions (ascending colon $[\mathrm{AC}]$, transverse colon [TC], descending colon [DC], rectosigmoid [RS], and stool) at a given time. $^{14}$

$(\% \mathrm{AC} \times 1+\% \mathrm{TC} \times 2+\% \mathrm{DC} \times 3+\% \mathrm{RS} \times 4+\%$ stool $\times 5) / 100=\mathrm{GC}$

Ascending colon half-emptying time ( $\left.\mathrm{AC} \mathrm{t}_{1 / 2}\right)$ was calculated by linear interpolation of ascending colon content at all times when imaging demonstrated isotope in the ascending colon, which is from 4 hours to 48 hours. Values of $A C t_{1 / 2}$ that were estimated over 100 hours were censored to be 100 hours.

Participants were not taking any prescription or over the counter medications for the 48 hours prior to and during the testing of gastrointestinal and colonic transit.

\section{Anorectal manometry and balloon expulsion studies}

We performed anorectal manometry and balloon expulsion tests as previously described; theses included traditional and high resolution manometry, ${ }^{6}$ and the maximum resting and squeeze anal pressures were expressed as $\mathrm{mmHg}$. After the manometry study, a latex balloon was inserted into the rectum and filled with $50 \mathrm{~mL}$ water. Additional weights were subsequently added if the patient was un- able to spontaneously expel the balloon from the rectum. Added balloon weight to facilitate balloon expulsion from the rectum was censored at weights between $470 \mathrm{~g}$ and $586 \mathrm{~g}^{15}$

\section{Measurements of colonic compliance and tone}

Endoscopy and colonic tube placement. Twenty-nine patients underwent an intracolonic motility study, including measurement of colonic compliance. Patients were usually selected for colonic motility testing based on longevity of symptoms and failure to respond to diverse treatments.

After discontinuing medications which have potential effects on colonic motility for 48 hours, the colon was cleansed with 2-5 liters of polyethylene glycol 3350 electrolyte solution, and the patient fasted the night before the procedure. Colonic motor functions were measured with an assembly consisting of 6 manometric sensors (each $5 \mathrm{~cm}$ apart) and a $10 \mathrm{~cm}$-long infinitely compliant balloon linked to an electronic, rigid piston barostat. The balloon was positioned by trained endoscopists into the left colon with the aid of unsedated flexible sigmoidoscopy and a Teflon guidewire that was inserted into the proximal descending colon (confirmed with fluoroscopy) through the endoscope's biopsy channel. The catheter was inserted into the colon along the Teflon guidewire so that the barostat balloon was typically located in the descending colon. The 6 manometric sensors recorded pressure through water perfused catheters.

Procedure for measuring colonic compliance and tone. The methods for measurements of colonic compliance (with stepwise distensions increasing by $4 \mathrm{mmHg}$ at each step, lasting 1 minute, and recording balloon volume during the second 30 seconds of each minute), tone, and phasic pressures are described in the literature ${ }^{16-23}$ and briefly summarized here.

After measuring colonic compliance, operating pressure within the balloon was set at $2 \mathrm{mmHg}$ above the minimum distending pressure (the pressure at which respiratory excursions during deep inspiration were accompanied by a noticeable deflection in the balloon volume). Then, fasting colonic tone and motility were assessed at the operating pressure for 20 minutes, followed by a standard $1000 \mathrm{kcal}$ meal $(750 \mathrm{~mL}$ milkshake containing $53 \%$ fat, $35 \%$ carbohydrate, and $12 \%$ protein) and measurement of postprandial colonic motility and tone during 60 minutes after ingestion of the meal. Neostigmine ( $1 \mathrm{mg}$, diluted in $5 \mathrm{~mL}$ of saline) was administered into a forearm vein by a physician, with continuous hemodynamic monitoring over 1-2 minutes. Colonic tone and phasic pressure activity were recorded for 15 minutes. Colonic compliance was then reassessed with an identical protocol. 


\section{Analysis of Colonic Tone, Compliance, and High Amplitude Propagated Contractions}

Colonic tone, reflected in the intra-balloon volume at the operating pressure, was calculated by averaging the colonic volume throughout the periods of assessment, as in previous studies. ${ }^{19,20}$

Compliance was summarized by the volumes at $12 \mathrm{mmHg}$ and $20 \mathrm{mmHg}$ pressure, normalized by subtracting the volumes recorded at $4 \mathrm{mmHg}$ distension. ${ }^{24}$

High amplitude propagated contractions were identified by amplitude $\geq 75 \mathrm{mmHg}$ propagation over at least $20 \mathrm{~cm}$ and propagation velocity of up to $2.2 \mathrm{~cm} / \mathrm{second}$ during the first hour after the $1000 \mathrm{kcal}$ meal. ${ }^{25}$

\section{Statistical Methods}

Data were expressed as median values with 25 th-75th percentile or mean values with standard deviation (SD). The MannWhitney rank sum test (SigmaPlot 12 Software, Systat Software Inc, Chicago, IL, USA) was used to assess the overall gastrointestinal transit studies, according to the presence or absence of evacuation disorders, and gender.

Table 1A. Demographics and Past History of the Patients with Slow Colonic Transit Identified by Scintigraphy

\begin{tabular}{lc}
\hline \multicolumn{1}{c}{ Number } & 207 \\
\hline Age (mean $\pm \mathrm{SD}, \mathrm{yr})$ & $41.3 \pm 15.3$ \\
Female $(\mathrm{n}[\%]$ ) & $155(74.9)$ \\
$\mathrm{BMI}\left(\right.$ mean $\left.\pm \mathrm{SD}, \mathrm{kg} / \mathrm{m}^{2}\right)$ & $23.1 \pm 4.3$ \\
Prior history of abdominal or pelvic surgery (n [\%]) & $107(51.7)$ \\
Diabetes (n [\%]) & $6(2.9)$ \\
Hypothyroidism [n (\%)] & $29(14.0)$ \\
Thyroid replacement (n [\%]) & $28(13.5)$ \\
Parkinson's disease (n [\%]) & $1(0.5)$ \\
Fibromyalgia (n [\%]) & $14(6.8)$ \\
Migraine (n [\%]) & $17(8.2)$ \\
Anxiety disorders (n [\%]) & $15(7.2)$ \\
Depression (n [\%]) & $27(13.0)$ \\
Medications (n [\%]) & \\
$\mu$-Opioid agonist & $33(15.9)$ \\
Tricyclic agents & $7(3.4)$ \\
Selective serotonin reuptake inhibitor & $52(25.1)$ \\
Benzodiazepine & $40(19.3)$ \\
GABA analogue & $31(15.0)$ \\
\hline
\end{tabular}

BMI, body mass index; GABA, gamma-aminobutyric acid. Data show number (\%) unless otherwise stated.

\section{Results}

\section{Patient Demographics and Past History}

Among a total of 207 patients with slow colonic transit by scintigraphy, 155 were females and the mean age was $41.3 \pm 15.3$ years $(\mathrm{SD})$ and the mean BMI was $23.1 \pm 4.3 \mathrm{~kg} / \mathrm{m}^{2}$. There were 29 patients (14.0\%) with treated hypothyroidism, 33 (15.9\%) with chronic opioid use, and 88 (42.5\%) taking antidepressants, gammaaminobutyric acid (GABA) agents or benzodiazepines (Table 1A). There were 99 patients taking medications that cause constipation; among them, 52 patients (52.5\%) had evacuation disorders. In addition, $51.7 \%$ (107/207) had undergone prior abdominal or pelvic surgery (details provided in Table 1B: 55 patients had undergone surgery once, 23 patients twice, and 20 patients $\geq 3$ times).

\section{Effect of Evacuation Disorder on Overall Colonic Transit}

Among the 207 patients with slow colonic transit, there were 113 patients with evacuation disorders $(\mathrm{ED}+\mathrm{ve})$ and 94 without evacuation disorders (ED-ve, 31 by clinical findings and 63 by anorectal manometry or balloon expulsion test). There were no significant differences in age and BMI between $\mathrm{ED}+\mathrm{ve}$ and $\mathrm{ED}$-ve groups. However, there was significant difference in the gender distribution between the 2 groups (females; $\mathrm{ED}+\mathrm{ve}, 66.4 \%$ vs $\mathrm{ED}$ ve, $85.1 \% ; P=0.002$ ).

There were no significant differences in gastric emptying, small bowel transit, and overall colonic transit (GC24, GC48, and AC $t_{1 / 2}$ ) between $\mathrm{ED}+\mathrm{ve}$ and ED-ve groups. In subgroup analysis by

Table 1B. Prior History of Abdominal or Pelvic Surgery

\begin{tabular}{lr}
\hline Prior history of abdominal or pelvic surgery (n [\%]) & $107(51.7)$ \\
Cholecystectomy & $42(20.3)$ \\
Appendectomy & $30(14.5)$ \\
Pelvic surgery except hysterectomy & $20(9.7)$ \\
Colectomy & $11(5.3)$ \\
Genitourinary surgery & $9(4.3)$ \\
Anorectal surgery & $8(3.9)$ \\
Caesarean section & $7(3.4)$ \\
Small bowel resection & $6(2.9)$ \\
Ileostomy & $4(1.9)$ \\
Prostate surgery & $3(1.4)$ \\
Gastrectomy & $2(1.0)$ \\
Hysterectomy (among 155 females) & $30 / 155(19.4)$
\end{tabular}


gender, there were no significant differences in gastric emptying, small bowel transit, and overall colonic transit between the 2 groups (Table 2). In subgroup analysis by gender, there were no significant differences in gastric emptying, small bowel transit, and overall colonic transit or $\mathrm{AC}_{1 / 2}$.

Moreover, there was no significant difference in left colon regional percentages of radioactivity between $\mathrm{ED}+\mathrm{ve}$ and $\mathrm{ED}$-ve (Table 3).

\section{Effect of Gender on Overall Transit in Studies of Entire Cohort with Slow Overall Colonic Transit}

There were significant differences in age and BMI, as well as gastric emptying, small bowel transit, and overall colonic transit at 24 and 48 hours, and $\mathrm{AC} \mathrm{t}_{1 / 2}$ between males and females with slow colonic transit (Table 4), even with adjustment using age and BMI as covariates.

Table 2. Comparison of Gastric Emptying, Small Bowel Transit, and Colon Transit According to the Presence of Evacuation Disorder

\begin{tabular}{|c|c|c|c|c|c|}
\hline & \multicolumn{2}{|c|}{ Patients with evacuation disorders $(\mathrm{n}=113)$} & \multicolumn{2}{|c|}{ Patients without evacuation disorders $(\mathrm{n}=94)$} & \multirow{2}{*}{$P$-value } \\
\hline & $\mathrm{n}$ & Median (IQR) & $\mathrm{n}$ & Median (IQR) & \\
\hline Age $(y r)$ & 113 & $39.0(27.0-52.0)$ & 94 & $43.5(30.0-52.3)$ & 0.298 \\
\hline $\mathrm{BMI}\left(\mathrm{kg} / \mathrm{m}^{2}\right)$ & 102 & $21.9(19.7-25.6)$ & 89 & $23.3(20.7-25.1)$ & 0.119 \\
\hline$\%$ females & 113 & 66.4 & 94 & 85.1 & 0.002 \\
\hline $\mathrm{GE}$ at $2 \mathrm{hr}(\%)$ & 108 & $55.0(37.5-71.0)$ & 87 & $58.0(43.0-72.0)$ & 0.256 \\
\hline $\mathrm{GE}$ at $4 \mathrm{hr}(\%)$ & 111 & $92.0(85.0-98.0)$ & 87 & $93(86.3-98.0)$ & 0.565 \\
\hline $\mathrm{CF}$ at $6 \mathrm{hr}(\%)$ & 113 & $33.0(10.0-65.0)$ & 94 & $46.5(20.0-86.0)$ & 0.060 \\
\hline GC $24 \mathrm{hr}$ & 113 & $1.3(1.1-1.7)$ & 94 & $1.5(1.2-1.7)$ & 0.068 \\
\hline GC $48 \mathrm{hr}$ & 50 & $1.9(1.7-2.5)$ & 64 & $2.1(1.8-2.6)$ & 0.087 \\
\hline$A C t_{1 / 2}(h r)$ & 81 & $29.0(18.1-40.0)$ & 73 & $23.2(17.3-35.3)$ & 0.332 \\
\hline
\end{tabular}

IQR, interquartile range; BMI, body mass index; GE, gastric emptying; $\mathrm{CF}$, colonic filling; $\mathrm{GC}$, geometric center; $\mathrm{AC} \mathrm{t}_{1 / 2}$, ascending colon half-emptying time.

Table 3. Comparison of Left Regional Colon Transit According to the Presence of Evacuation Disorder

\begin{tabular}{|c|c|c|c|c|c|}
\hline \multirow{2}{*}{$\begin{array}{l}\text { Percentage of } \\
\text { radioactivity }\end{array}$} & \multicolumn{2}{|c|}{ Patients with evacuation disorders $(\mathrm{n}=113)$} & \multicolumn{2}{|c|}{ Patients without evacuation disorders $(\mathrm{n}=94)$} & \multirow{2}{*}{$P$-value } \\
\hline & $\mathrm{n}$ & Median (IQR) & $\mathrm{n}$ & Median (IQR) & \\
\hline $\mathrm{DC}+\mathrm{RS}$ at $24 \mathrm{hr}(\%)$ & 89 & $0.0(0.0-7.0)$ & 73 & $0.0(0.0-5.5)$ & 0.967 \\
\hline $\mathrm{DC}+\mathrm{RS}$ at $48 \mathrm{hr}(\%)$ & 43 & $8.0(0.0-31.0)$ & 56 & $18.0(0.0-34.8)$ & 0.470 \\
\hline DRS at $24 \mathrm{hr}(\%)$ & 89 & $0.0(0.0-8.5)$ & 73 & $0.0(0.0-7.0)$ & 0.911 \\
\hline DRS at $48 \mathrm{hr}(\%)$ & 43 & $16.0(0.0-47.0)$ & 56 & $23.0(0.0-46.5)$ & 0.745 \\
\hline
\end{tabular}

IQR, interquartile range; DC, descending colon; RS, rectosigmoid colon; DRS, descending colon, rectosigmoid colon and stool.

Table 4. Gastric Emptying, Small Bowel Transit and Colon Transit According to Gender

\begin{tabular}{|c|c|c|c|c|c|}
\hline & \multicolumn{2}{|c|}{ Males $(\mathrm{n}=52)$} & \multicolumn{2}{|c|}{ Females $(\mathrm{n}=155)$} & \multirow{2}{*}{$P$-value } \\
\hline & $\mathrm{n}$ & Median (IQR) & $\mathrm{n}$ & Median (IQR) & \\
\hline Age (yr) & 52 & $48.5(31.3-62.0)$ & 155 & $39.0(27.0-51.0)$ & 0.006 \\
\hline $\mathrm{BMI}\left(\mathrm{kg} / \mathrm{m}^{2}\right)$ & 47 & $24.4(22.1-26.5)$ & 144 & $21.8(19.6-24.6)$ & 0.005 \\
\hline $\mathrm{GE}$ at $2 \mathrm{hr}(\%)$ & 48 & $71.5(55.0-87.0)$ & 147 & $55.0(38.0-69.0)$ & $<0.001^{\mathrm{a}}$ \\
\hline $\mathrm{GE}$ at $4 \mathrm{hr}(\%)$ & 50 & $97.0(91.0-100.0)$ & 148 & $91.5(82.3-97.0)$ & $<0.001^{\mathrm{a}}$ \\
\hline $\mathrm{CF} 6 \mathrm{hr}(\%)$ & 52 & $74(18.5-100.0)$ & 155 & $62.0(11.0-65.0)$ & $<0.001^{\mathrm{a}}$ \\
\hline GC 24 & 52 & $1.9(1.5-2.4)$ & 155 & $1.3(1.0-1.6)$ & $<0.001^{\mathrm{a}}$ \\
\hline GC 48 & 12 & $2.5(2.2-2.7)$ & 102 & $2.0(1.7-2.5)$ & $0.004^{\mathrm{a}}$ \\
\hline $\mathrm{ACt}_{1 / 2}(\mathrm{hr})$ & 38 & $18.3(15.0-25.9)$ & 116 & $29.7(19.6-40.0)$ & $<0.001^{\mathrm{a}}$ \\
\hline
\end{tabular}

${ }^{\mathrm{a}}$ Analysis of transit measurements used age and BMI as covariates.

$\mathrm{IQR}$, interquartile range; BMI, body mass index; GE, gastric emptying; $\mathrm{CF}$, colonic filling; $\mathrm{GC}$, geometric center; AC $\mathrm{t}_{1 / 2}$, ascending colon half-emptying time. 
Table 5. Measurements of Colonic Compliance, Motility, and Tone in Subgroups According to the Presence of Evacuation Disorders

\begin{tabular}{|c|c|c|c|c|c|}
\hline & \multicolumn{2}{|r|}{ ED-ve } & \multicolumn{2}{|r|}{$\mathrm{ED}+\mathrm{ve}$} & \multirow{2}{*}{$P$-value } \\
\hline & $\mathrm{n}$ & Median (IQR) & $\mathrm{n}$ & Median (IQR) & \\
\hline \multicolumn{6}{|l|}{$\begin{array}{l}\text { Barostat balloon volumes in response at different distension } \\
\text { pressures (compliance) before meal }\end{array}$} \\
\hline at $12 \mathrm{mmHg}$ & 19 & $61(45.0-97.0)$ & 10 & $80.5(37.8-116.8)$ & 0.668 \\
\hline at $20 \mathrm{mmHg}$ & 19 & $143(102.0-180.0)$ & 10 & $182.5(131.0-207.5)$ & 0.179 \\
\hline \multicolumn{6}{|l|}{ Barostat balloon volumes in response at IOP (colonic tone) } \\
\hline Before meal & 19 & $111.7(81.6-125.6)$ & 10 & $122.2(115.1-158.8)$ & 0.056 \\
\hline After meal & 19 & $99.8(63.4-138.6)$ & 10 & $108.8(64.6-125.4)$ & 0.946 \\
\hline $\begin{array}{l}\text { Barostat balloon volumes at IOP (colonic tone) in response to } \\
\text { iv injection of neostigmine }\end{array}$ & 19 & $80.8(43.7-108.7)$ & 7 & $63.5(29.3-89.3)$ & 0.497 \\
\hline \multicolumn{6}{|l|}{$\begin{array}{l}\text { Barostat balloon volumes at different distension pressures } \\
\text { (compliance) after iv neostigmine }\end{array}$} \\
\hline at $12 \mathrm{mmHg}$ & 18 & $63(28.5-76.3)$ & 10 & $53.0(19.8-82.8)$ & 0.796 \\
\hline at $20 \mathrm{mmHg}$ & 18 & $146.5(86.0-165.8)$ & 10 & $133.5(85.8-216.3)$ & 0.654 \\
\hline High amplitude propagated contractions after meal (n [\%]) & 19 & $0(0.0)$ & 10 & $2(20.0)$ & $0.111^{\mathrm{a}}$ \\
\hline Irregular colonic contractility in postprandial period (n [\%]) & 19 & $6(31.6)$ & 10 & $1(10.0)$ & $0.367^{\mathrm{a}}$ \\
\hline
\end{tabular}

IQR, interquartile range; ED-ve, absence of evacuation disorders; ED+ve, presence of evacuation disorders; IOP, intraoperating pressure; iv, intravenous ${ }^{a}$ Fisher's exact test.

\section{Colonic Motor Parameters in 29 Patients with Slow Colonic Transit}

Among 207 patients, 29 patients (19 ED-ve and $10 \mathrm{ED}+\mathrm{ve})$ underwent intraluminal measurement of colonic motility. Table 5 shows that there were no significant differences in the comparisons of colonic compliance and colonic tone between the 2 groups. Among 29 patients, only $2 \mathrm{ED}+$ ve patients had postprandial high amplitude propagated contractions (first hour), whereas, none of the ED-ve patients had high amplitude propagated contractions $(P$ $=0.111$ ). Seven patients ( $1 \mathrm{ED}+\mathrm{ve}$ and $6 \mathrm{ED}$-ve) had irregular contractile activity in the left colon.

\section{Discussion}

In this retrospective review of 1553 patients seen by one gastroenterologist at a tertiary referral medical center, 207 patients had slow colonic transit based on scintigraphic findings. Among the 207 patients, 113 patients (54.6\%) were diagnosed with evacuation disorders based on abnormal anorectal manometry (mean resting anal sphincter pressure $>90 \mathrm{mmHg}$ ) or balloon expulsion test, consistent with the previously reported prevalence rates of $63.5 \%$ with defecatory disorders among 52 patients with documented slow colonic transit. ${ }^{26}$ We classified 31 patients without evacuation disorders only by digital rectal examination performed by a single expert with extensive experience. Normal resting anal tone does not rule out dyssynergia. The components of digital rectal examination in this study included specific maneuvers to appraise anorectal dysfunction including asking the patient to strain, assessing pelvic floor descent on inspection and palpation, and palpating the pelvic floor for tenderness or paradoxical contraction during simulated straining to evacuate the examining finger. The literature documents that a carefully performed digital rectal examination by a highly experienced expert has shown $75 \%$ sensitivity, $87 \%$ specificity, and $97 \%$ positive predictive value. $^{27}$

Among patients in the current cohort of 207 patients, $15.9 \%$ were chronic $\mu$-opioid users and $42.5 \%$ were being treated with antidepressants, GABA agents, or benzodiazepines, all of which are associated with constipation in community-based studies. ${ }^{28,29}$ These data suggest that, even in patients with drug-associated chronic constipation and slow colonic transit, it is still important to exclude a rectal evacuation disorder, since $52.5 \%$ of the current cohort who were taking these medications was $\mathrm{ED}+\mathrm{ve}$.

This study showed that there were no significant differences in gastric emptying, small bowel transit, and overall colonic transit between $\mathrm{ED}+$ ve and ED-ve patients with slow colonic transit. Furthermore, there was no significant difference in the left colon regional transit at 24 hours and 48 hours in the two groups with documented slow colonic transit. Our previous study showed that overall colonic transit was delayed in patients with dyssynergic def- 
ecation and in those with slow transit constipation in the absence of evacuation disorders, relative to healthy volunteers. ${ }^{6}$ We previously showed the higher proportion of isotope in the left colon at 48 hours in patients with dyssynergic defecation compared to those with only slow transit constipation. However, in that study, patients with either normal or slow colonic transit were included in the group of dyssynergic defecation. In the present study, the detailed colonic transit study did not demonstrate regional differences in location of the isotope at 24 or 48 hours to differentiate those with evacuation disorders among constipated patients with objectively delayed colonic transit, compared to those without evacuation disorders. Therefore, these data confirm that it is necessary to perform tests to exclude evacuation disorders, even in constipated patients with objectively slow colonic transit, and that the location of markers of colonic transit does not sufficiently differentiate patients with or without evacuation disorders. The similarity of distribution of isotope in the colon, especially at 48 hours, also suggests that there may be a colonic motor dysfunction in addition to the evacuation disorders in the patients who were ED+ve and had slow colonic transit. Indeed, this is supported by the observation that there were very few patients with postprandial high amplitude propagated contractions among those who were ED+ve (as discussed below).

We observed gender-related effects on colonic transit, gastric emptying, and small bowel transit in constipated patients with slow colonic transit, with slower transit profiles in females compared to males. Previously, we showed, in the cohort of 208 healthy volunteers, that colonic transit was slower in females than in males. ${ }^{7}$ This result is also consistent with other studies in Asian cohorts. ${ }^{30,31}$ Moreover, in patients with irritable bowel syndrome and patients with defecation disorders, there were differences in colonic transit between men and women. ${ }^{7,32}$ Female sex hormones, particularly progesterone, have been proposed as possible etiologic factors in slow transit constipation. Epidemiologic studies have shown a higher incidence of slow transit constipation in young females during their reproductive years than in males. ${ }^{33,34}$ Progesterone impairs smooth muscle contraction, decreases serotonin transporter, and increases serotonin levels in mice. ${ }^{35}$ Females with slow transit constipation had overexpression of progesterone receptors in colon muscle and colon epithelial cells. ${ }^{35,36}$ These female sex hormones may explain the difference of overall colonic transit by gender in the different groups.

In this study, 29 patients underwent intraluminal assessment of colonic motility with manometry and a barostat. We did not observe any differences in colonic tone and compliance during fasting, postprandially, or in response to neostigmine, and only $2 \mathrm{ED}+\mathrm{ve}$ pa- tients had postprandial high amplitude propagated contractions. As expected, the patients with slow transit constipation who were EDve had a paucity of high amplitude propagated contractions, consistent with the published literature in patients with severe chronic constipation as previously reviewed. ${ }^{37}$ The presence of irregular contractile activity in the pelvic colon in patients with constipation was previously described by Connell. ${ }^{38}$ It was interesting to note that this feature was more prevalent in ED-ve patients (that is, patients with slow colonic transit unassociated with evacuation disorders), rather than $\mathrm{ED}+\mathrm{ve}$ patients, and this is consistent with observations of Connell. These findings on non-high amplitude propagated contractions colonic motor activity differ somewhat from those obtained with higher resolution fiberoptic manometry in adults with slow transit constipation, which showed that cyclic propagating motor patterns were not increased postprandially in contrast to observations in normal controls. ${ }^{39}$ We acknowledge that the sample is relatively small and the data are presented to corroborate the overall results of colonic motor function appraised by scintigraphy. We have previously shown that evacuation disorders may result in reversible inhibition of colonic tone. ${ }^{40}$ However, further studies in larger numbers would be required to more thoroughly appraise the hypothesis that the evacuation disorders were associated with reversible inhibition of colonic tone and phasic contractions in the colon, resulting in delayed colonic transit.

In conclusion, our data suggest that it is important to consider the possibility of evacuation disorders in patients with chronic constipation, even in the presence of objectively delayed colonic transit. The regional colonic transit profile does not conclusively identify evacuation disorders in constipated patients with delayed colonic transit. In patients with chronic constipation and objectively slow colonic transit, females had slower gastric, small bowel, and colonic transit than males.

Financial support: Michael Camilleri is supported by grants from the National Institutes of Health (No. RO1-DK92179 and R56-DK67071).

\section{Conflicts of interest: None}

Author contributions: Seon-Young Park: conceptualization, medical records and literature search, and writing of the manuscript; Duane Burton: analysis of colonic transit measurements; Irene Busciglio: analysis of colonic transit, motility, tone, and compliance measurements; Deborah Eckert: conceptualization and care of patients; and Michael Camilleri: conceptualization, literature 
search, care of patients, and writing of the manuscript.

\section{References}

1. Sethi S, Mikami S, Leclair J, et al. Inpatient burden of constipation in the United States: an analysis of national trends in the United States from 1997 to 2010. Am J Gastroenterol 2014;109:250-256.

2. Pare P, Ferrazzi S, Thompson WG, Irvine EJ, Rance L. An epidemiological survey of constipation in canada: definitions, rates, demographics, and predictors of health care seeking. Am J Gastroenterol 2001;96:31303137.

3. Suares NC, Ford AC. Prevalence of, and risk factors for, chronic idiopathic constipation in the community: systematic review and metaanalysis. Am J Gastroenterol 2011;106:1582-1591.

4. Choung RS, Locke GR 3rd, Schleck CD, Zinsmeister AR, Talley NJ. Cumulative incidence of chronic constipation: a population-based study 1988-2003. Aliment Pharmacol Ther 2007;26:1521-1528.

5. Lembo A, Camilleri M. Chronic constipation. N Engl J Med 2003;349:1360-1368

6. Nullens S, Nelsen T, Camilleri M, et al. Regional colon transit in patients with dys-synergic defaecation or slow transit in patients with constipation. Gut 2012;61:1132-1139.

7. Shin A, Camilleri M, Nadeau A, et al. Interpretation of overall colonic transit in defecation disorders in males and females. Neurogastroenterol Motil 2013;25:502-508.

8. Rao SS, Mudipalli RS, Stessman M, Zimmerman B. Investigation of the utility of colorectal function tests and Rome II criteria in dyssynergic defecation (Anismus). Neurogastroenterol Motil 2004;16:589-596.

9. Cremonini F, Mullan BP, Camilleri M, Burton DD, Rank MR. Performance characteristics of scintigraphic transit measurements for studies of experimental therapies. Aliment Pharmacol Ther 2002;16:1781-1790.

10. Kolar GJ, Camilleri M, Burton D, Nadeau A, Zinsmeister AR. Prevalence of colonic motor or evacuation disorders in patients presenting with chronic nausea and vomiting evaluated by a single gastroenterologist in a tertiary referral practice. Neurogastroenterol Motil 2014;26:131-138.

11. Fox JC, Fletcher JG, Zinsmeister AR, Seide B, Riederer SJ, Bharucha AE. Effect of aging on anorectal and pelvic floor functions in females. Dis Colon Rectum 2006;49:1726-1735.

12. Rao SS, Hatfield R, Soffer E, Rao S, Beaty J, Conklin JL. Manometric tests of anorectal function in healthy adults. Am J Gastroenterol 1999:94:773-783.

13. Camilleri M, Iturrino J, Bharucha AE, et al. Performance characteristics of scintigraphic measurement of gastric emptying of solids in healthy participants. Neurogastroenterol Motil 2012;24:1076-e562.

14. Deiteren A, Camilleri M, Bharucha AE, et al. Performance characteristics of scintigraphic colon transit measurement in health and irritable bowel syndrome and relationship to bowel functions. Neurogastroenterol Motil 2010;22:415-423.e95.

15. Pemberton JH, Rath DM, Ilstrup DM. Evaluation and surgical treatment of severe chronic constipation. Ann Surg 1991;214:403-411; discussion 411-413.
16. O’Brien MD, Camilleri M, von der Ohe MR, et al. Motility and tone of the left colon in constipation: a role in clinical practice? Am J Gastroenterol 1996;91:2532-2538.

17. Bharucha AE, Camilleri M, Zinsmeister AR, Hanson RB. Adrenergic modulation of human colonic motor and sensory function. Am J Physiol 1997;273(5 Pt 1):G997-G1006.

18. Ford MJ, Camilleri M, Zinsmeister AR, Hanson RB. Psychosensory modulation of colonic sensation in the human transverse and sigmoid colon. Gastroenterology 1995;109:1772-1780

19. Bharucha AE, Camilleri M, Haydock S, et al. Effects of a serotonin 5-HT4 receptor antagonist SB-207266 on gastrointestinal motor and sensory function in humans. Gut 2000;47:667-674.

20. Chial HJ, Camilleri M, Ferber I, et al. Effects of venlafaxine, buspirone, and placebo on colonic sensorimotor functions in healthy humans. Clin Gastroenterol Hepatol 2003;1:211-218.

21. Soll AH, Yamada T, Park J, Thomas LP. Release of somatostatinlike immunoreactivity from canine fundic mucosal cells in primary culture. Am J Physiol 1984;247:G558-G566.

22. Odunsi ST, Camilleri M, Bharucha AE, et al. Reproducibility and performance characteristics of colonic compliance, tone, and sensory tests in healthy humans. Dig Dis Sci 2010;55:709-715.

23. Delgado-Aros S, Chial HJ, Camilleri M, et al. Effects of a kappa-opioid agonist, asimadoline, on satiation and GI motor and sensory functions in humans. Am J Physiol Gastrointest Liver Physiol 2003;284:G558G566.

24. Mouchli MA, Camilleri M, Lee T, et al. Evaluating the safety and the effects on colonic compliance of neostigmine during motility testing in patients with chronic constipation. Neurogastroenterol Motil 2016.

25. Malcolm A, Camilleri M. Coloanal motor coordination in association with high-amplitude colonic contractions after pharmacological stimulation. Am J Gastroenterol 2000;95:715-719.

26. Ravi K, Bharucha AE, Camilleri M, Rhoten D, Bakken T, Zinsmeister AR. Phenotypic variation of colonic motor functions in chronic constipation. Gastroenterology 2010;138:89-97.

27. Tantiphlachiva K, Rao P, Attaluri A, Rao SS. Digital rectal examination is a useful tool for identifying patients with dyssynergia. Clin Gastroenterol Hepatol 2010;8:955-960.

28. Talley NJ, Fleming KC, Evans JM, et al. Constipation in an elderly community: a study of prevalence and potential risk factors. Am J Gastroenterol 1996;91:19-25

29. Talley NJ, Jones M, Nuyts G, Dubois D. Risk factors for chronic constipation based on a general practice sample. Am J Gastroenterol 2003;98:1107-1111.

30. Cho KO, Jo YJ, Song BK, Oh JW, Kim YS. Colon transit time according to physical activity and characteristics in South Korean adults. World J Gastroenterol 2013;19:550-555.

31. Chan YK, Kwan AC, Yuen H, et al. Normal colon transit time in healthy Chinese adults in Hong Kong. J Gastroenterol Hepatol 2004;19:12701275 .

32. Manabe N, Wong BS, Camilleri M, Burton D, McKinzie S, Zinsmeister AR. Lower functional gastrointestinal disorders: evidence of abnormal colonic transit in a 287 patient cohort. Neurogastroenterol Motil 
2010;22:293-e82.

33. Knowles CH, Scott SM, Rayner C, et al. Idiopathic slow-transit constipation: an almost exclusively female disorder. Dis Colon Rectum 2003;46:1716-1717.

34. Preston DM, Lennard-Jones JE. Severe chronic constipation of young women: 'idiopathic slow transit constipation'. Gut 1986;27:41-48.

35. Guarino M, Cheng L, Cicala M, Ripetti V, Biancani P, Behar J. Progesterone receptors and serotonin levels in colon epithelial cells from females with slow transit constipation. Neurogastroenterol Motil 2011;23:575e210.

36. Cong P, Pricolo V, Biancani P, Behar J. Abnormalities of prostaglandins and cyclooxygenase enzymes in female patients with slow-transit constipa- tion. Gastroenterology 2007;133:445-453.

37. Bharucha AE. High amplitude propagated contractions. Neurogastroenterol Motil 2012;24:977-982.

38. Connell AM. The motility of the pelvic colon. II. Paradoxical motility in diarrhoea and constipation. Gut 1962;3:342-348.

39. Dinning PG, Wiklendt L, Maslen L, et al. Colonic motor abnormalities in slow transit constipation defined by high resolution, fibre-optic manometry. Neurogastroenterol Motil 2015;27:379-388.

40. Mollen RM, Salvioli B, Camilleri M, et al. The effects of biofeedback on rectal sensation and distal colonic motility in patients with disorders of rectal evacuation: evidence of an inhibitory rectocolonic reflex in humans? Am J Gastroenterol 1999;94:751-756. 